\title{
Correction to: Neuropsychiatric symptoms and striatal monoamine availability in early Parkinson's disease without dementia
}

\author{
Yoon-Sang $\mathrm{Oh}^{1}$ • Jean Hee Kim ${ }^{1}$. Sang-Won Yoo ${ }^{1}$ • Eo-Jin Hwang ${ }^{2}$. Chul Hyoung Lyoo ${ }^{3}$ Kwang-Soo Lee ${ }^{1}$. \\ Joong-Seok Kim ${ }^{1}$
}

Published online: 10 November 2020

(C) Fondazione Società Italiana di Neurologia 2020

Correction to: Neurological Sciences (2020) https://doi.org/10.1007/s10072-020-04859-8

The originally figure 1 was published online in black and Publisher's note Springer Nature remains neutral with regard to jurisdictional claims in published maps and institutional affiliations.

white. Author confirmed to change the figure in colored image in online and in print version.

The online version of the original article can be found at https://doi.org/ 10.1007/s10072-020-04859-8

Joong-Seok Kim

neuronet@catholic.ac.kr

1 Department of Neurology, Seoul St. Mary's Hospital, College of Medicine, The Catholic University of Korea, 222, Banpo-daero, Seocho-gu, 06591 Seoul, Republic of Korea

2 Department of Radiology, College of Medicine, The Catholic University of Korea, Seoul, Republic of Korea

3 Department of Neurology, Gangnam Severance Hospital, Yonsei University College of Medicine, Seoul, Republic of Korea 

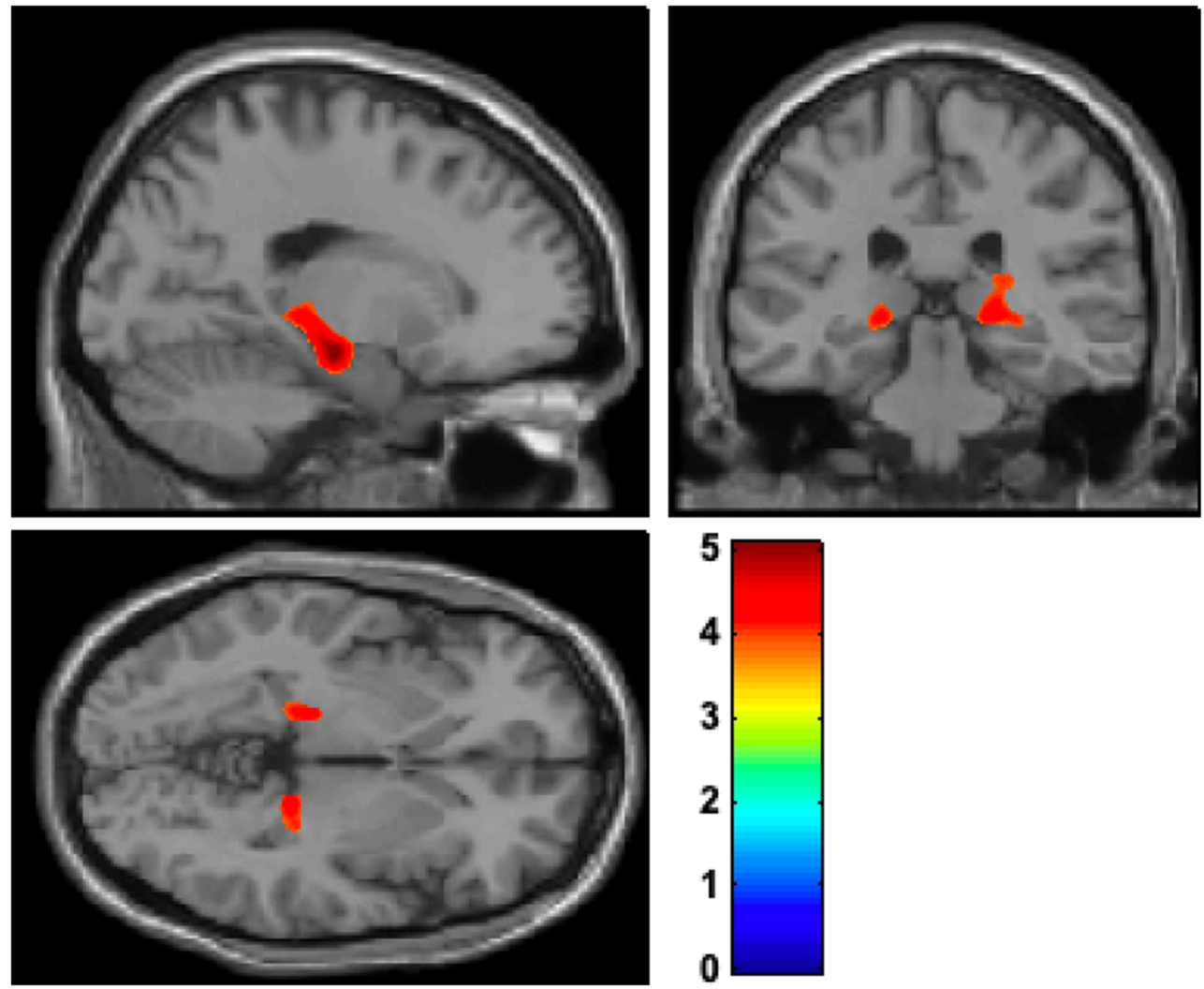

Fig. 1 Voxel-based comparison of ${ }^{18} \mathrm{~F}-\mathrm{N}$-(3-fluoropropyl)-2betacarbon ethoxy-3beta-(4-iodophenyl) nortropane positron emission tomography $\left({ }^{18}\right.$ F-FPCIT PET) controlling for age between Parkinson's disease patients with no neuropsychiatric symptoms and neuropsychiatric symptoms. The differences of the standardized uptake value ratios
(SUVRs) between the two groups were demonstrated in the coloredregion. The SUVR values in the thalamus of patients with neuropsychiatric symptoms decreased more than those of patients with no neuropsychiatric symptoms. $t$ values are indicated by the color bar 